\title{
Renovación de autoridades en ANALEcta VetERINARIA
}

La Plata, 15 de diciembre de 2017

Sr. Decano de la

Facultad de Ciencias Veterinarias

de la Universidad Nacional de La Plata

Prof. Dr. Claudio Barbeito

Me dirijo a Ud. a los efectos de presentar mi renuncia al cargo de Director de la Revista ANALECTA VETERINARIA, en el que me desempeño en carácter ad honórem.

Tuve el honor de ser designado como tal en el año 1998. Han pasado 20 años de una tarea que tuvo la misión de posicionar a la revista en altos estándares de reconocimiento. En este período ANALECTA VETERINARIA fue la primera revista científica veterinaria en estar colocada en la Web en nuestro país y que fuera calificada por el Caicyt-Conicet como "Nivel 1 superior de excelencia”. Fue una tarea en parte solitaria pero, a partir de su gestión como Decano, se logró conformar un grupo de trabajo de excelencia, no solo desde lo científico sino desde las cualidades personales de sus integrantes, lo que permitió mantenerse estable durante cuatro años.

Esto me permite ponerle un fin a mi actividad, un cambio de ciclo, que es coherente con mi pensamiento de renovación de cargos y funciones, quedando un grupo de trabajo consolidado para la continuidad de ANALECTA VETERINARIA.

No me queda más que agradecer a los sucesivos decanos por la confianza puesta en mí en estos 20 años, a los integrantes de las distintas comisiones y especialmente los actuales y, finalmente, a su gestión por afianzar el interés en la Revista.

Sin más, me despido con un atento saludo,

Prof. Dr. Néstor Oscar Stanchi

Estimados lectores de ANALECTA Veterinaria:

Los párrafos que anteceden corresponden a la dimisión presentada oportunamente por el que fuera, hasta el año pasado, director de la revista de los últimos 20 años. No nos quedan más que palabras de agradecimiento para el Dr. Stanchi, por haber continuado el camino iniciado en el año 1905 por los editores de la entonces denominada Revista de la Facultad de Agronomía y Veterinaria.

El alejamiento del Dr. Stanchi se hace coincidente con el recambio de autoridades de nuestra Facultad. Por esta razón, y contando con el apoyo de las nuevas autoridades, decidimos reestructurar el rol desempeñado por algunos de sus integrantes, incorporar nuevos colaboradores y realizar algunos cambios en la presentación de este nuevo volumen de la Revista que hoy está viendo la luz.

Es nuestro deseo que todos aquellos autores que nos han acompañado hasta el presente lo sigan haciendo y que nuevos autores se sumen para engrandecer ANALECTA Veterinaria, una revista de todos y para todos.

Consejo Editorial

ANALECTA VETERINARIA

ANALECTA Vet 2018; 38(1): 1

Impresa ISSN 03655 14-8 Electrónica ISSN 1514-2590

doi.org/10.24215/15142590e018 